\title{
Review
}

\section{Monoamine Oxidase-B Inhibitors for the Treatment of Parkinson's Disease: Past, Present, and Future}

\author{
Yu-Yan Tan ${ }^{\mathrm{a}}$, Peter Jenner ${ }^{\mathrm{b}}$ and Sheng-Di Chen ${ }^{\mathrm{a}, \mathrm{c}, *}$ \\ ${ }^{a}$ Department of Neurology and Institute of Neurology, Ruijin Hospital, Shanghai Jiao Tong University School of \\ Medicine, Shanghai, China \\ ${ }^{\mathrm{b}}$ Neurodegenerative Diseases Research Group, Institute of Pharmaceutical Sciences, Faculty of Health Sciences \\ and Medicine, King's College, London, UK \\ ${ }^{\mathrm{c}}$ Lab for Translational Research of Neurodegenerative Diseases, Institute of Immunochemistry, Shanghai Tech \\ University, Shanghai, China
}

Accepted 30 November 2021

Pre-press 21 December 2021

\begin{abstract}
Monoamine oxidase-B (MAO-B) inhibitors are commonly used for the symptomatic treatment of Parkinson's disease (PD). MAO-B inhibitor monotherapy has been shown to be effective and safe for the treatment of early-stage $\mathrm{PD}$, while MAO-B inhibitors as adjuvant drugs have been widely applied for the treatment of the advanced stages of the illness. MAO-B inhibitors can effectively improve patients' motor and non-motor symptoms, reduce "OFF" time, and may potentially prevent/delay disease progression. In this review, we discuss the effects of MAO-B inhibitors on motor and non-motor symptoms in PD patients, their mechanism of action, and the future development of MAO-B inhibitor therapy.
\end{abstract}

Keywords: Monoamine oxidase-B inhibitors, Parkinson's disease, selegiline, rasagiline, safinamide

\section{INTRODUCTION}

Parkinson's disease (PD) is a common chronic neurodegenerative disease, characterized by abnormal formation of Lewy neurites and (or) Lewy bodies with intraneuronal aggregates of proteins (mainly $\alpha$-synuclein) spreading from medulla oblongata to pontine tegmentum, midbrain, mesocortex, and neocortex in an ascending pattern, and a decreased

\footnotetext{
${ }^{*}$ Correspondence to: Sheng-Di Chen, Department of Neurology and Institute of Neurology, Ruijin Hospital, Shanghai Jiao Tong University School of Medicine, Shanghai, China; Lab for Translational Research of Neurodegenerative Diseases, Institute of Immunochemistry, Shanghai Tech University, Shanghai, China. E-mail: chensd@rjh.com.cn.
}

number of dopaminergic neurons in substantia nigra (SN) leading to deficiency of dopamine [1-3]. There are approximately 6.1 million PD patients worldwide, and the prevalence increases with age, reaching $1 \%$ to $3 \%$ in the population over 65 years of age [4, 5]. Common motor symptoms of PD are bradykinesia, resting tremor, rigidity, postural instability, and gait disorder, which are often accompanied by various non-motor symptoms such as sleep disturbance, autonomic dysfunction, depression, and fatigue that can severely affect daily life $[6,7]$. Although the disease cannot be cured, therapeutic strategies have been developed, including drug treatment, surgical techniques, and rehabilitation, which can alleviate symptoms and might have the potential to slow disease progression [8]. 
Levodopa is considered the most effective symptomatic treatment for $\mathrm{PD}$ and is required at some point in the illness by almost all patients $[8,9]$. Nevertheless, the long-term use of levodopa can induce motor complications such as motor fluctuations ('wearing off'; 'on-off') and dyskinesia [10]. Dopamine agonists (DAs) or enzyme inhibitors, including catechol-O-methyl-transferase (COMT) inhibitors and monoamine oxidase B (MAO-B) inhibitors, are commonly applied as adjuvants to levodopa to alleviate motor complications. Commonly utilized COMT inhibitors, such as entacapone and opicapone, inhibit levodopa degradation in the periphery while MAO-B inhibitors penetrate the blood-brain barrier, inhibit central MAO activity in the CNS and so reduce dopamine degradation [10]. MAO-B inhibitors have been shown to have excellent efficacy and safety during the early stages of PD as well as when used as adjunctive therapy in advanced illness [11-13]. Clinical studies have shown that a longer duration of MAO-B inhibitor exposure was associated with a reduction in levodopa consumption and a slower rate of clinical decline $[14,15]$. Currently approved MAO-B inhibitors include the irreversible inhibitors, such as selegiline and rasagiline, and the reversible inhibitor, safinamide [10-16]. In this review, we will discuss the effect of MAO-B inhibitors on motor and non-motor symptoms of PD, their mechanism of action and the future development of MAO-B inhibitors.

\section{MECHANISM OF ACTION OF MAO-B INHIBITORS}

\section{MAO-B inhibitors regulate the MAO-B activity}

Monoamine oxidase (MAO) is a riboflavin protein distributed on the outer membrane of mitochondria. It catalyzes the oxidative deamination of tyramine and monoamine neurotransmitters such as dopamine, phenethylamine, 5-hydroxytryptamine, and norepinephrine $[17,18]$. There are two MAO isoenzymes: MAO-A and MAO-B. MAO-A is mainly distributed in the gastrointestinal tract, platelets, and heart, and can promote the metabolism of tyramine-containing substances in food so avoiding hypertensive crises caused by the accumulation of tyramine ("cheese reaction"). MAO-A also exists in catecholaminergic neurons, such as dopaminergic neurons in $\mathrm{SN}$, norepinephrine neurons in locus coeruleus, etc. [18]. MAO-B is mainly distributed in platelets and glial cells, and total MAO activity within the brain is composed of approximately 20\% MAO-A and $80 \%$ MAO-B [19-22]. Both MAO-A and MAO-B regulate the amine neurotransmitters, including dopamine. MAO-A metabolizes dopamine in presynaptic neurons, while MAO-B metabolizes dopamine released to synaptic cleft and taken up by glial cells. The number of glial cells was shown to increase with age, and in neurodegenerative diseases, as expected, the activity of MAO-B also increased [23-25]. MAO-B inhibitors inhibit MAO-B activity in the brain, block dopamine catabolism, enhance dopamine signaling, and selectively enhance dopamine levels at synaptic cleft [21]. Preclinical studies have shown that rasagiline, a second-generation MAO-B inhibitor, is 3-15 times more potent than selegiline in in vivo studies in rats [26]. Compared with selegiline (10 mg/day), even low doses of rasagiline ( 0.5 to $2 \mathrm{mg} /$ day $)$ can benefit patients with PD [13, 27-29]. Furthermore, safinamide, the latest-generation MAO-B inhibitor that also possesses sodium and calcium channel blocking activity, shows 5,000 times higher selectivity for MAO-B than MAO-A, while the traditional MAOB inhibitor selegiline only shows 127 times higher selectivity in in vitro studies using rat brain [30]. Besides blocking dopamine reuptake, safinamide also exerts therapeutic effects via inhibition of glutamate release and voltage-dependent opening of sodium channels and modulation of non-dopaminergic systems such as calcium channels $[31,32]$.

\section{MAO-B inhibitors may have disease modifying effects}

For PD patients, disease modification is defined as the ability of a given agent to slow, arrest, or rescue the process of nigral dopaminergic cell death, and thus slow clinical progression and deterioration $[22,33,34]$. MAO-B metabolism of dopamine may lead to the formation of toxic metabolites, such as hydrogen peroxide and dihydroxyacetaldehyde, thus MAO-B inhibitors may protect neurons by inhibiting these toxic processes [22]. Both selegiline and rasagiline have neuroprotective effects related to their propargylamine structure which is independent of their inhibition on MAO-B [35-37]. Selegiline and rasagiline can increase the expression level of nerve growth factor, glial cell-derived neurotrophic factor, brain-derived neurotrophic factor, and other nerve growth factors, therefore exerting a neuroprotective role [16]. Rasagiline can inhibit apoptosis by directly or indirectly activating anti-apoptotic factors such as 
Bcl-2 and Bcl-xL and inhibiting the expression of proapoptotic factors such as $\mathrm{Bax}[38,39]$. Rasagiline may have a neuroprotective advantage over selegiline due to a different pathway of metabolism. For example, both selegiline and rasagiline can reduce oxygen-glucose deprivation-induced cell death in PC12 cell lines. However, L-methamphetamine, a metabolite of selegiline, not aminoindan, the major metabolite of rasagiline, enhanced oxygen-glucose deprivation-induced cell death by $70 \%$ [37]. In addition, brain SPECT scans showed that rasagiline had a potential neuroprotective effect by stabilizing regional cerebral blood flow perfusion in patients with PD [40]. Unlike selegiline and rasagiline, safinamide blocks sodium and calcium channels, regulates glutamate release, and reduces excitotoxicity to dopaminergic neurons [30]. Animal studies have shown that safinamide inhibits microglial cell activation and protects dopaminergic neurons from degeneration [41].

\section{Effects of MAO-B inhibitors on mitochondria and cell apoptosis}

Mitochondrial dysfunction occurs in PD characterized by decreased activity of mitochondrial complex I and increased reactive oxygen species production [42]. In vitro studies have shown that MAO-B inhibitors can improve the function of brain mitochondria by inhibiting the activity of nitric oxide synthase and reducing the production of hydrogen peroxide [43]. In addition, MAO-B inhibitors can regulate membrane permeability changes in mitochondria caused by neurotoxins and oxidative stress and inhibit calcium efflux in mitochondria [44]. For example, the toxin 1-methyl-4-phenyl-1,2,3,6tetrahydropyridine (MPTP) is oxidized by MAO-B to form 1-methyl-4-phenylpyridine ion $\left(\mathrm{MPP}^{+}\right)$after passing through the blood-brain barrier. $\mathrm{MPP}^{+}$then inhibits the activity of mitochondrial complex I, resulting in cell death and the release of reactive oxygen leading to dopaminergic cell death [45]. Animal experiments have shown that both rasagiline and selegiline can significantly reduce the neurotoxicity of MPTP [46].

\section{Effects of MAO-B inhibitors on alpha-synuclein aggregation}

Alpha-synuclein is a major component of Lewy bodies. In vitro studies have shown that MAO-B inhibitors can delay the nucleation phase of alpha- synuclein aggregation, and this may potentially lead to a reduction in the rate of disease progression [47]. MAO-B inhibitors promote alpha-synuclein to form cyclic or dimeric structures and prevent it from forming sheet-like structures and linear structures required for aggregation [48]. Based on the above multiple pharmacological mechanisms, MAO-B inhibitors have demonstrated excellent efficacy in early and advanced $\mathrm{PD}$, and might have disease modifying effects in PD.

\section{PD SYMPTOMS TREATED BY MAO-B INHIBITORS}

PD-related symptoms treated with MAO-B inhibitors are detailed in Table 1.

\section{Improvement of motor symptoms}

According to the Guidelines for Adult Parkinson's Disease published by National Institute for Health and Care Excellence (NICE) in 2017 [9], MAO-B inhibitors are recommended as first-line therapies for patients with early PD whose motor symptoms are not affecting their quality of life. For PD patients with dyskinesia or motor fluctuations, MAO-B inhibitors may be selected as adjuncts to levodopa. Treatments for the Motor Symptoms of PD from the International Parkinson and Movement Disorder Society Evidence-Based Medicine Review in 2018 [49] recommend the use of MAO-B inhibitor selegiline and rasagiline as effective monotherapy for early $\mathrm{PD}$. Yet, it seems that rasagiline is clinically effective in adjunct to DA therapy for early/stable PD, but safinamide is ineffective as an adjunct to DA. Both

Table 1

PD-related symptoms covered by this review and selection of corresponding MAO-B inhibitors

\begin{tabular}{ll}
\hline Symptoms & MAO-B inhibitor \\
\hline Motor symptoms & \\
Early monotherapy & Selegiline, rasagiline \\
Adjunct therapy in advanced & Rasagiline, safinamide \\
PD & \\
Non-motor symptoms & \\
Sleep disturbance (insomnia) & Rasagiline \\
Sleep disturbance (excessive & Selegiline \\
daytime somnolence) & \\
Fatigue & Rasagiline \\
Mental and cognitive & Selegiline, rasagiline, \\
disorders & safinamide \\
Bladder dysfunction & Rasagiline, safinamide \\
Improvement of gait & Selegiline, rasagiline, \\
& safinamide \\
\hline
\end{tabular}




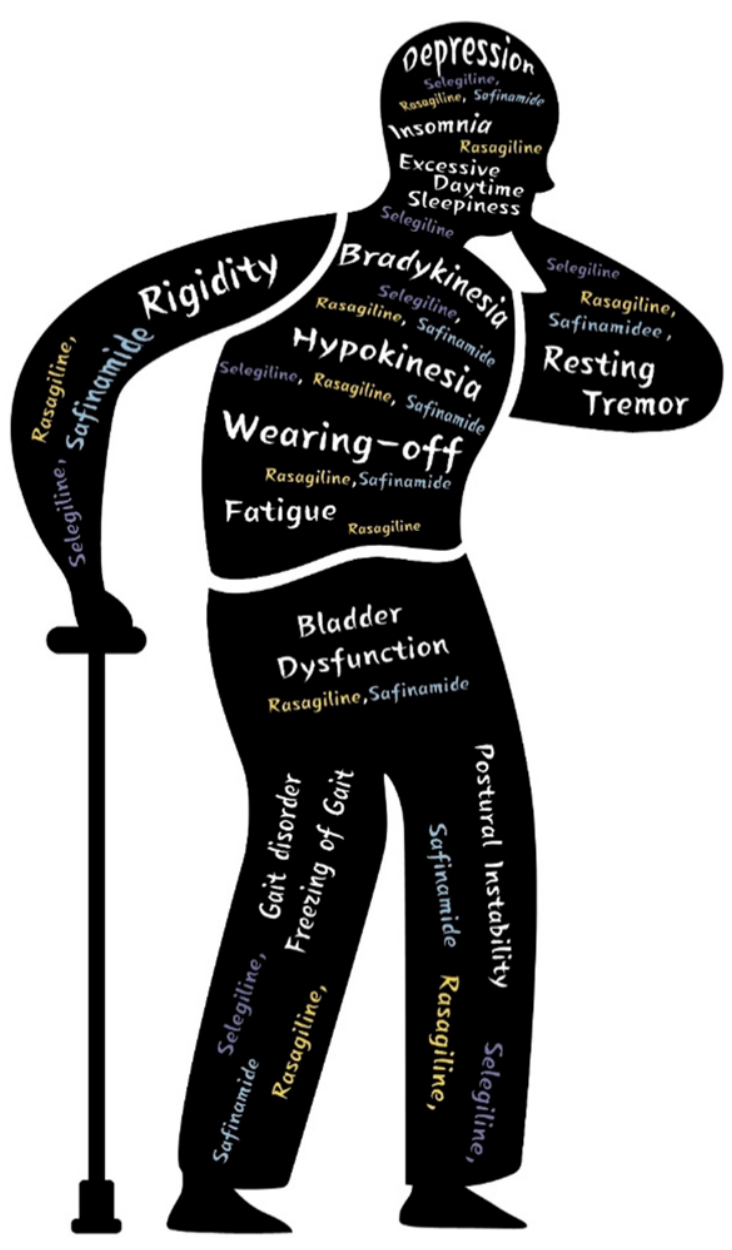

Fig. 1. Selection of MAO-B inhibitors according to PD related symptoms.

rasagiline and safinamide are effective in the treatment of motor fluctuations, and there is insufficient evidence for selegiline. 2020 Chinese guidelines for the Treatment of Parkinson's disease (fourth edition) states that MAO-B inhibitors can be used in early PD patients and add-on therapy for advanced PD patients and that rasagiline is a better choice compared to selegiline in improving motor complications [50].

\section{Monotherapy in early PD (first-line therapy)}

The PD-MED study [51] was a long-term, large, pragmatic, randomized controlled study (real-world study) that compared the long-term control of symptoms and improvement in the quality of life of patients with early PD treated with levodopa, DAs, or MAO-B inhibitors. For levodopa-sparing therapy, participants treated with MAO-B inhibitors were significantly more likely to discontinue their allocated drug class than those allocated DAs ( $72 \%$ vs. $50 \%$ ). Discontinuation was mainly due to side effects, and a small group was due to an absence of efficacy. However, after exposure to levodopa, initial treatment with MAO$B$ inhibitors showed small but significantly better benefits in PDQ-39 mobility scores (1.4 points better), cognition, PDQ-39 summary index (0.8 points better) but not the quality of life from EuroQol EQ$5 \mathrm{D}$ scale compared with initial treatment with DAs. Rates of dyskinesia were similar between the MAO-B inhibitors group and the DAs group, but motor fluctuations were higher in the DAs group. A possible explanation for better efficacy of MAO-B inhibitor with lower levodopa equivalent doses (LED) compared with DAs (695 mg/day vs. $768 \mathrm{mg} /$ day) might be that levodopa could be less effective when added to DAs than MAO-B inhibitors, which needs to be further validated [51]. DAs are generally considered to be more effective than MAO-B inhibitors, but according to the PD MED study, MAO-B inhibitors as initial levodopa-sparing therapy were at least as effective as DAs [51].

Selegiline. Selegiline monotherapy may delay disease progression in patients with early PD and delay the need for levodopa therapy. A small-sample-sized double-blind study showed that selegiline delayed the need for levodopa by 548.9 days compared to 312.1 days in patients treated with placebo [52]. For treatment-naïve PD patients, two double-blind studies were published in 1992 and 1998, which included 52 and 157 patients, respectively. In those studies, patients were treated with a placebo or selegiline. Compared with placebo, selegiline improved motor symptoms of PD patients and delayed the development of disability and the need for levodopa compared to placebo [53, 54]. A Phase III, 12-week randomized, double-blind study performed in 2017, which included 292 Japanese patients with early PD who were randomized into the placebo or selegiline group, showed that selegiline monotherapy significantly improved the unified Parkinson's disease rating scale (UPDRS) score in patients with early PD $(p=0.0005)$ and was well tolerated [55].

Rasagiline. Rasagiline can improve motor symptoms and has potential disease-modifying effects in early PD patients. These results have been observed in Asians, Europeans, and Americans. The TEMPO study [12] that was published in 2002 evaluated the efficacy of rasagiline in early PD patients from 
Europe and the USA. After 26 weeks of treatment, the adjusted effect size for total UPDRS was -4.20 units improvement of $1 \mathrm{mg}$ rasagiline and -3.56 units improvement of $2 \mathrm{mg}$ rasagiline $(p<0.001)$ compared with placebo. In the extension study of TEMPO [56], $46 \%$ of patients were controlled with rasagiline monotherapy at the second year of follow-up without the need for additional dopaminergic medications.

The 2009 ADAGIO study [57] evaluated the disease-modifying effect of rasagiline monotherapy in patients with early treatment-naive PD. Three stratified primary endpoints based on UPDRS were set to determine the disease-modifying effect of $1 \mathrm{mg} / 2 \mathrm{mg}$ rasagiline by a study design of early-start treatment with rasagiline for 72 weeks and delay-start treatment with placebo for 36 weeks followed by $1 \mathrm{mg} / 2 \mathrm{mg}$ rasagiline till 72 weeks. The first endpoint was that rate of total UPDRS change in $1 \mathrm{mg} / 2 \mathrm{mg}$ rasagiline group had superiority to placebo during 12-36 weeks treatment; the second endpoint was a better change of UPDRS score between baseline and 72 weeks in the early-start treatment than delayed treatment groups; the third endpoint was that rate of UPDRS change during 48 to 72 weeks in the early-start treatment was noninferiority to delayed treatment groups. The study results showed that the $1 \mathrm{mg}$ rasagiline group met all 3 stratified endpoints but not the $2 \mathrm{mg}$ rasagiline group. Between 12 and 36 weeks of treatment, rates of UPDRS scores changes per week were significantly smaller in the $1 \mathrm{mg}$ and $2 \mathrm{mg}$ rasagiline groups compared with placebo group $(0.09 \pm 0.02$ vs. $0.14 \pm 0.01, p=0.01 ; 0.07 \pm 0.02$ vs. $0.14 \pm 0.01$, $p<0.001$ ); at 72 weeks the total UPDRS score change from baseline was less worsening in $1 \mathrm{mg}$ earlystart group than delayed-start group ( $2.82 \pm 0.53$ vs. $4.50 \pm 0.56, p=0.02$ ), but no significant difference in $2 \mathrm{mg}$ early-start group compared with delayedstart group ( $3.47 \pm 0.50$ vs. $3.11 \pm 0.50, p=0.60)$; for the third stratified endpoint, the rate of UPDRS scores improvement per week in the $1 \mathrm{mg}$ and $2 \mathrm{mg}$ early-dose groups was not inferior to that in the delayed-dose group $(0.085 \pm 0.02$ vs. $0.085 \pm 0.02$, $0.094 \pm 0.01$ vs. $0.065 \pm 0.02$, both $p<0.001)$. Since the $2 \mathrm{mg}$ rasagiline group did not meet the second endpoints, the disease-modifying effect of rasagiline was not conclusive and should need more sensitive evaluation scales and methods in a longer-term study to determine its disease-modifying effects in more motor and non-motor areas.

The CHORUS study [58] published in 2018 evaluated the efficacy of rasagiline in Chinese patients with early PD. A total of 127 patients with early treatment-naive PD were included in this randomized controlled study. The results showed that the decrease in total UPDRS scores was significantly greater in the $1 \mathrm{mg} /$ day rasagiline group than the placebo group $(-3.18 \pm 0.95$ vs. $-0.18 \pm 0.98, p=0.025)$. Moreover, a Phase III study evaluated the efficacy and safety of rasagiline in 224 Japanese early PD patients and showed that after 26 weeks of treatment, rasagiline monotherapy significantly improved the MDS-UPDRS II + III scores compared with placebo $(-6.39,95 \%$ CI $[-8.530,-4.250], p<0.0001)$ [59]. In the extension study of the second period, all the patients who completed the randomized trial (95 on placebo and 103 on rasagiline) entered the extension and received $1 \mathrm{mg}$ rasagiline for another 26 weeks. The mean change in MDS-UPDRS (Part II + III) from baseline to 52 weeks was -2.8 points in both the placebo-rasagiline $(95 \% \mathrm{CI}[-4.05,-1.59]$ and rasagiline-rasagiline (95\% CI $[-4.57,-1.01]$ groups [60], suggesting that long-term treatment with rasagiline consistently improved motor symptoms in patients with good safety and tolerability, and late start of rasagiline treatment did not compromise its efficacy in this study.

\section{Symptomatic adjunct therapy in early or stable PD}

In patients with early or stable PD, MAO-B inhibitors could relieve symptoms and reduce levodopa dosage and might have beneficial effects on neuroprotection which still need investigation because of a lack of sufficient evidence.

Selegiline. The DATATOP study showed that treatment with selegiline alone or in adjunct with vitamin E may delay the use of levodopa and the progression of disability caused by PD in patients with early PD [61]. A 5-year prospective, randomized, doubleblind, placebo-controlled study published in 1999 evaluated the efficacy of selegiline as an adjunct to conventional levodopa in patients with early PD [62]. PD patients without levodopa treatment or on levodopa treatment for no longer than 12 months were randomized either to selegiline or placebo group. Before starting the study medication, the levodopa dose was titrated to the individual requirements of each patient. The primary endpoint was the time when levodopa had to be increased by $>50 \%$ of the titrated dose. The results showed that selegiline significantly delayed the median time to reach the primary endpoint compared with the placebo group (4.9 years vs. 2.6 years, $p=0.027)$. The mean levodopa dose 
changed only slightly over the 5 years of treatment in the selegiline group but rose markedly in the placebo group. Meanwhile, the lower levodopa dosage in the selegiline group was accompanied by at least equal therapeutic efficacy, indicating that selegiline was effective to relieve motor symptoms in adjunct therapy with levodopa. Another study showed that patients treated with selegiline plus levodopa for 5 years had a significantly improved UPDRS score compared with the placebo plus levodopa group, and the mean dosage of levodopa was $19 \%$ higher with placebo than with selegiline ( $p=0.0002)$ [63].

Some studies have explored the feasibility of selegiline combined with DAs. In 1991, Nappi et al. studied the effects of selegiline added on lisuride therapy and found that mean lisuride dosage could be reduced without deterioration of the clinical effects [64]. In 1995, Calzetti et al studied that L-deprenyl (10 mg daily) as an adjunct to low-dose bromocriptine (up to $25 \mathrm{mg}$ daily) compared with bromocriptine alone or bromocriptine plus placebo and found that selegiline combined regimens produced a mildly significant improvement in the majority of clinical rating scales, a stabilization of clinical status up to 12 months, and a smaller proportion of patients in need of levodopa at 24 months [65]. However, both lisuride and bromocriptine are ergot-related dopamine agonist, and bromocriptine has the risk of fibrotic cardiac valvulopathies from long-term use. Lyons et al. reported a study of PD patients with levodopa-induced motor fluctuations and pramipexole related adverse events (AEs) of excessive daytime sleepiness, pedal edema, hallucinations and impulsecontrol disorders, investigating the effect of adding orally disintegrating selegiline on the reduction of DA-related AEs [66]. Results showed that DA-related AEs were reduced or resolved at week 12 in most subjects, while UPDRS activities of daily living scores were improved obviously $(p<0.005)$, indicating that the addition of orally disintegrating selegiline with decreasing dosages of DAs mainly reduced DA related AEs without affecting efficacy.

Rasagiline. Early PD patients whose conditions were not adequately controlled with their current DA treatment (ropinirole $\geq 6 \mathrm{mg} / \mathrm{d}$ or pramipexole $\geq 1.0 \mathrm{mg} / \mathrm{d}$ ) were randomized either to $1 \mathrm{mg}$ rasagiline or placebo [67]. The results showed that adjunct therapy with rasagiline improved the total UPDRS score $(-3.6 \pm 0.7$ vs. $-1.2 \pm 0.7, p=0.012)$ and UPDRS motor score $(-3.4 \pm 0.5$ vs. $-1.6 \pm 0.5$, $p=0.007$ ) from baseline to week 18 , with no increase in clinically relevant adverse reactions compared with placebo. Another study [68] evaluated the efficacy of rasagiline as an adjunct with pramipexole (P2B001, $0.3 \mathrm{mg}$ pramipexole $/ 0.75 \mathrm{mg}$ rasagiline or $0.6 \mathrm{mg}$ pramipexole $/ 0.75 \mathrm{mg}$ rasagiline) in patients with early treatment-naive PD. One hundred forty-nine patients were randomized to receive placebo, different doses combination of pramipexole/rasagiline for 12 weeks. Significant improvements were found in total UPDRS score, PDQ-39, the UPDRS motor and activities of daily living in both $0.3 \mathrm{mg}$ pramipexole $/ 0.75 \mathrm{mg}$ rasagiline combination and $0.6 \mathrm{mg}$ pramipexole $/ 0.75 \mathrm{mg}$ rasagiline combination compared with the placebo group.

Safinamide. A Phase III double-blind trial published in 2012 explored the efficacy of safinamide adjunct therapy in early PD patients previously treated with stable dose of a single DA. The patients were randomized to placebo, $100 \mathrm{mg} /$ day safinamide, or $200 \mathrm{mg} /$ day safinamide groups. The results showed that $100 \mathrm{mg} /$ day of safinamide improved the UPDRS III scores in patients with early PD compared with placebo ( -6.0 vs. $-3.6, p=0.0419)$. However, improvement was not evident in patients in the $200 \mathrm{mg} /$ day group compared with placebo group ( -3.9 vs. $-3.6, p=0.6504)$ [69]. In the extension period of the above study, the primary efficacy endpoint was the time from baseline to further intervention by increasing DA dose, adding other PD treatment, or discontinuing therapy due to lack of efficacy. Although patients receiving safinamide $100 \mathrm{mg} /$ day experienced a significantly lower rate of intervention compared with placebo ( $25 \%$ vs. $51 \%$, $p<0.05$ ), the pooled data from the safinamide groups failed to reach statistical significance for the median time from baseline to additional drug intervention (pooled safinamide vs. placebo [559 vs. 466 days, $p=0.3342]$ ) [70]. The MDS evidence-based recommendations in 2018 suggested that safinamide as an adjunct to DAs in early PD is "non-efficacious" and "not useful" in PD without motor fluctuations.

\section{Adjunct therapy in advanced PD}

Selegiline. So far, few studies have reported on selegiline adjunct therapy in advanced PD. A 6-week study, which included 96 PD patients with marked symptom fluctuations, showed a greater proportion of patients with gait improvement (56\% vs. $30.4 \%$ ) and greater improvement in symptom score ( 0.25 vs. $0.15)$ in the $5 \mathrm{mg}$ bid selegiline group compared with placebo. Nevertheless, selegiline failed to prolong the 
patient's "ON" time [71]. In a clinical study in 1991, the addition of selegiline to the original regimen significantly reduced daily levodopa use and tended to shorten the daily "OFF" time in 7 PD patients with symptom fluctuations [72].

Rasagiline. The PRESTO study [13] published in 2005 enrolled a total of 472 European and USA patients with PD who had received levodopa with motor fluctuations and a daily "OFF" time of $\geq 2.5$ h. Patients were randomized to placebo, $1 \mathrm{mg} /$ day or $0.5 \mathrm{mg} /$ day of rasagiline. After 26 weeks of treatment, the daily "OFF" time was reduced by $0.94 \mathrm{~h}(p<0.001)$ and $0.49 \mathrm{~h}(p=0.02)$ in the $1 \mathrm{mg} /$ day and $0.5 \mathrm{mg} /$ day groups, respectively, compared with placebo, and the activities of daily living during "OFF" time and the motor performance during the "ON" time were improved. The LARGO study [73], published in the same year, showed that $1 \mathrm{mg} /$ day rasagiline improved symptoms in patients who had received levodopa and developed motor fluctuations, reduced the mean daily "OFF" time significantly compared with placebo $(-1.18 \mathrm{~h}$ vs. $-4.0 \mathrm{~h}, p=0.0001$ ), and increased daily "ON" time without troublesome dyskinesia $(0.85 \mathrm{~h}$ vs. $0.03 \mathrm{~h}$; $p=0.0005$ ). Rasagiline showed similar efficacy to entacapone. In addition, sub-study analyses of the LARGO study [74] showed that rasagiline significantly reduced the UPDRS motor OFF scores, and rasagiline had a trend in reducing the UPDRS-ADL OFF score, but entacapone had no significant effect $(-1.95$ vs. $1.27, p=0.14)$.

A randomized controlled study from 2013, which investigated the efficacy of rasagiline as adjunctive therapy to levodopa treatment in Chinese patients with PD [75], showed that the mean adjusted total daily "OFF" time shortened more significantly in the rasagiline group than in the placebo group $(-1.75 \pm 1.69$ h vs. $-0.69 \pm 1.44 \mathrm{~h}, p<0.001)$. The 2018 CHORAL study [76] also showed that rasagiline as an adjuvant was able to significantly shorten the mean total daily "OFF" time in the Chinese patients who received levodopa and experienced motor fluctuations compared with placebo $(-1.25 \mathrm{~h}$ vs. $-0.76 \mathrm{~h}, p=0.023)$. It also improved the daily functioning and overall health status of patients and was well tolerated by patients.

Furthermore, two studies conducted in 2019 in Japanese PD patients who received levodopa and experienced wearing-off phenomena showed that patients treated with rasagiline $1 \mathrm{mg}$ or $0.5 \mathrm{mg}$ for 26 weeks had a $0.84 \mathrm{~h}$ and $0.60 \mathrm{~h}$ decrease in "OFF" time compared with placebo $(p=0.0006$ and 0.0140 , respectively), and patients treated with rasagiline $1 \mathrm{mg}$ for 52 weeks had a $0.89 \mathrm{~h}$ decrease in "OFF" time from baseline (95\% CI -1.376 to -0.399 ) [77, 78]. Thus, adjunctive rasagiline treatment with levodopa was efficacious, with efficacy maintained for at least 52 weeks.

Safinamide. Although the pharmacological mechanisms of safinamide and rasagiline are different, studies showed that they were equally effective in inhibiting MAO-B action [79]. In Phase III multicenter, randomized, double-blind, 24-week trial published in 2014 , both $100 \mathrm{mg} /$ day and $50 \mathrm{mg}$ /day safinamide as an add-on treatment significantly prolonged the total "ON" time with no or non-troublesome dyskinesia compared with placebo $(1.36 \pm 2.625 \mathrm{~h}$ vs. $1.37 \pm 2.745 \mathrm{~h}$ vs. $0.97 \pm 2.375 \mathrm{~h}$ ). In addition, greater improvement was achieved in reduction of "OFF" time, UPDRS III assessment, and clinical global impression-correction scale (CGI-C) assessment in the safinamide group than the placebo group [80]. A randomized trial published in 2017 showed that in patients with PD who had an "OFF" time of at least $1.5 \mathrm{~h}$ per day, safinamide as an add-on therapy significantly prolonged "ON" time $(1.42 \pm 2.80 \mathrm{~h}$ vs. $0.57 \pm 2.47 \mathrm{~h}, p<0.001)$, reduced total daily "OFF" time without troublesome dyskinesia $(-1.56 \pm 2.35 \mathrm{~h}$ vs. $-0.54 \pm 2.21 \mathrm{~h}, p<0.001)$ and improved UPDRS III score rated during an "ON" phase $(-3.43 \pm 7.72$ vs. $-1.83 \pm 8.23, p=0.003$ ) compared with placebo [81]. Furthermore, a 24-week randomized, doubleblind, placebo-controlled Phase II/III study showed that for Japanese patients with PD who did not respond well to levodopa, the addition of $50 \mathrm{mg} /$ day or $100 \mathrm{mg} /$ day of safinamide resulted in an increase in the change of mean daily "ON" time by $1.39 \mathrm{~h}$ $(p=0.0002)$ and $1.66 \mathrm{~h}(p<0.0001)$ respectively, and improvement in patients' symptoms and signs compared with placebo [82].

\section{Non-motor symptoms}

The non-motor symptoms of PD involve multiple types and may occur at all stages of the disease, particularly sleep disturbance, fatigue symptoms, and neuropsychiatric symptoms.

\section{Sleep disturbance}

Approximately half of the newly diagnosed PD patients have subjective sleep discomfort, which is the second most common non-motor symptom in 
PD [83]. Sleep disturbances of PD patients comprise insomnia, excessive daytime sleepiness, rapid eye movement behavior disorder and sleep-related movement disorders, namely restless legs syndrome, etc. Disease progression, motor complications, dopaminergic medications, severe autonomic dysfunction, presence of hallucination were reported to be associated with sleep disorders for PD patients [84, 85].

Selegiline metabolites amphetamine derivatives have potential sympathomimetic effects and side effects affecting sleep. When combining the AE data from the long-term studies, insomnia was included in the most common AEs [86]. One may assume that amphetamine-like derivatives of selegiline worsen sleep quality supported by the onset of insomnia during chronic selegiline intake in PD patients [87], thus it needs to be taken in the morning and at noon. Selegiline may be tried in patients with excessive daytime sleepiness [50]. Gallazzi et al. reported that 45 PD patients with excessive daytime sleepiness, usually developed after the introduction of DAs, were treated with $10 \mathrm{mg}$ selegiline and the results showed a statistically significant improvement of somnolence but no change in the UPDRS III scores [88].

Rasagiline can improve sleep in PD patients when used as monotherapy or adjunct therapy. A 12-week prospective observational study showed that rasagiline adjunct to levodopa improved sleep outcomes compared with baseline, reduced mean sleep latency compared with levodopa alone $(-1.68 \pm 1.21 \mathrm{~h}$ vs. $-0.55 \pm 0.69 \mathrm{~h}, p=0.001)$, and prolonged mean total sleep time $(1.26 \pm 1.62 \mathrm{~h}$ vs. $0.32 \pm 0.70 \mathrm{~h}, p=0.026)$ [89]. Another randomized controlled trial showed that for PD patients with sleep disturbance, rasagiline had beneficial effects on the sleep quality as measured by polysomnography. Treatment with rasagiline also led to significantly decreased wake time after sleep onset, a number of arousals and percentage of light sleep, and improved daytime sleepiness as measured by the Epworth Sleepiness Scale compared with baseline. No correlations of polysomnographic sleep parameters or Parkinson's Disease Sleep Scale2 (PDSS2) score with motor function were found, indicating that effects of rasagiline on sleep were probably not related to motor improvement [90].

So far, only a few studies have reported on the effect of safinamide on sleep in PD patients. Some investigators evaluated the effects of safinamide treatment on non-motor symptoms of PD patients [91-94]. Patients treated with safinamide showed a significant reduction of PDSS2 and ESS scores [92]. SAFINONMOTOR study showed 6 months after starting with safinamide, sleep (NMSS-domain 2 and PSQI) was significantly improved in PD patients [93]. The efficacy of safinamide in PD patients with sleep disorders still needs further research and exploration in the future.

\section{Fatigue symptoms}

Fatigue is defined as an overwhelming sense of tiredness, lack of energy, and feeling of exhaustion, which is unrelated to physical activity. It is described as one of the most disabling symptoms of PD, occurring in about $50 \%$ of patients even at the early stages, negatively impacting the quality of life $[95,96]$. A post hoc analysis of the ADAGIO study [97] showed that, for treatment-naive PD patients, fatigue symptoms progressed more significantly in the placebo group than in rasagiline $1 \mathrm{mg} /$ day and $2 \mathrm{mg}$ /day groups ( 0.17 vs. 0.03 vs. -0.02$)$, and rasagiline monotherapy significantly delayed the progression of fatigue in patients. In a randomized controlled study in $2015,1 \mathrm{mg} /$ day of rasagiline significantly improved the Modified Fatigue Impact Scale score from baseline to 12 weeks of treatment compared with placebo in patients with confirmed PD who complained of moderate-to-severe fatigue (12 vs. 8.5, $p=0.003$ ) [98]. According to the 2018 MDS Evidence-based review for updates on treatments for the non-motor symptoms [99], rasagiline is considered "efficacious" for the treatment of fatigue in PD. The practice implication was "possibly useful" due to the small sample size. A prospective cohort study by De Micco et al. [100] found that safinamide treatment of motor fluctuating PD patients significantly reduced fatigue scores $(p=0.02)$. In the open-label prospective study SAFINONMOTOR, safinamide treatment improved the sleep/fatigue scores $(-35.8 \%$; $p=0.002)$ of PD patients [93]. This suggests that safinamide might be beneficial in improving fatigue in PD patients.

\section{Depression}

Depression is common in PD patients and frequently involves apathy and anhedonia. Disease duration, severity of motor symptoms, occurrence of motor complications, cognitive decline and dementia, anxiety, sleep disturbance, autonomic symptoms, etc., have been linked to increased risk of depression in PD patients [101]. Meta-analysis showed that MAO-B inhibitors could reduce the severity of depression symptoms in PD patients, especially in patients with early PD [102]. A French multicenter, double-blind, randomized, controlled study 
published in 1991 included a total of 93 PD patients who were randomized to receive either $10 \mathrm{mg} /$ day selegiline or placebo for 3 months [103]. The results showed that the 90-day Hamilton Depression Rating Scale (HDRS) score and mental UPDRS Scale score were more improved in the selegiline group than in the placebo group ( $p=0.005$ and $p<0.001$, respectively). In addition, the study showed that PD patients treated with selegiline adjunct with levodopa have significant improvement in MMSE and Beck Depression Inventory (BDI) scale scores than patients treated with levodopa only [104]. Furthermore, a 12-week, double-blind, placebo-controlled trial that evaluated the effect of $1 \mathrm{mg} /$ day rasagiline on depression and cognition in non-demented PD patients with depressive symptoms found that rasagiline may significantly reduce the total BDI-IA score in week 4 compared with placebo $(-5.46 \pm 0.73$ vs. $-3.22 \pm 0.67, p=0.026$ ) [105]. In addition, studies have shown that safinamide also improved emotional disorders in PD patients. The study also showed that at 6 months and 2 years, safinamide improved the emotional well-being score of the PDQ-39 questionnaire ( $p=0.0067$ and 0.0006 , respectively), the GRID Hamilton Rating Scale for Depression (GRIDHAMD) score ( $P=0.0408$ and 0.0027 , respectively), and reduced the risk of AEs of depression in PD patients compared with placebo $(p=0.0444$ and 0.005 , respectively) [106]. In a study of PD patients with fluctuating symptoms treated with safinamide in adjunct with levodopa, the 24-week treatment results showed that the improvement in GRID-HAMD score was greater in the $100 \mathrm{mg}$ /day adjunct therapy group than in the placebo group $(-0.8$ vs. $-0.3, p=0.0731)$ [80]. However, a meta-analysis of the effect of MAO-B inhibitors on the alleviation of depressive symptoms in PD based on randomized controlled trials showed that the short-term efficacy of MAO$\mathrm{B}$ inhibitors in the treatment of PD with depression is significant, but long-term evidence is insufficient [102].

\section{Bladder dysfunction}

Bladder dysfunction is one of the most common autonomic dysfunctions in PD patients, with an estimated incidence of 55\%-80\% [107]. In 2014, a 2-month open-label study evaluated changes in urodynamic parameters in patients with early mild PD before and after treatment with $1 \mathrm{mg} /$ day of rasagiline. The results showed that rasagiline significantly improved bladder function, increased bladder capacity (16\%), and first micturition sensation (34\%), and reduced residual urine volume $(-53 \%)$ in $\mathrm{PD}$ patients [107]. In 2021, a small retrospective analysis of urological symptoms in PD patients treated with safinamide [108] showed that the total score of Scale for Outcomes in Parkinson's disease for Autonomic Symptoms-Urinary subscale (SCOPAAUT-U) and subscale scores for micturition urgency, urinary incontinence, urinary frequency, and nocturia were significantly improved compared to baseline in patients receiving safinamide add-on therapy, suggesting that safinamide may contribute to the improvement of urinary symptoms of PD.

\section{Gait disorder}

With disease progression, severe gait disorders can lead to disability and quality of life decline in PD patients, where freezing of gait (FOG) is a common type of gait disorder in PD patients [109]. The prevalence of FOG is $46.62 \%$ in Chinese PD patients [110]. Studies suggested that MAO-B inhibitors selegiline and rasagiline can reduce the risk of developing FOG [111]. Analysis of data from 800 patients with early PD in the DATATOP study [112] showed that the application of selegiline could reduce the risk of developing FOG by 53\% $(p<0.0001)$. Moreover, a post hoc analysis of PRESTO and LARGO studies [113] revealed that compared with placebo, adjunct therapy with $1 \mathrm{mg}$ /day of rasagiline improved UPDRS postural stability $(-0.02$ vs. $-0.11, p<0.05)$ and gait score $(0.01$ vs. $-0.10, p<0.05)$ in $\mathrm{PD}$ patients. For PD patients who had received stable treatment for at least 6 months and had a FOG duration of $3.3 \pm 1.8$ years, rasagiline significantly improved UPDRS III, FOG-Q, and PDQ-39 quality of life scores (all $p<0.001$ ) [114]. For a pooled analysis of two randomized placebo-controlled studies, $100 \mathrm{mg} /$ day safinamide significantly improved mean UPDRS III score ( -5.15 vs. $-3.25, p=0.0003)$ and gait score ( -0.56 vs. $-0.34, p=0.0118)$ from baseline compared with placebo in patients with advanced PD [115].

To sum up, MAO-B inhibitors show good efficacy in treating patients with early and advanced PD. Compared with selegiline monotherapy or adjunct therapy mainly used in patients with early or stable PD and safinamide adjunct therapy mainly used in patients with advanced PD, rasagiline had high evidence-based efficacy in the monotherapy and adjunct therapy for early and advanced PD and significantly improved various motor and non-motor symptoms in PD patients. Binde et al. reported a 
meta-analysis that included 27 trials assessing the most effective MAO-B inhibitors for early or later PDs by evaluating both UPDRS score and serious AEs [116]. They found that all included MAO-B inhibitors were effective compared to placebo when given as monotherapy, while selegiline became more efficient than other MAO-B inhibitors when combined with levodopa, whether or not the duration of the disease was taken into account. In another subsequent meta-analysis of 79 publications, Binde et al. included DAs (cabergoline, pramipexole, ropinirole, rotigotine) and MAO-B inhibitors in the comparison, and interestingly, they found that all the investigated drugs to be effective compared with placebo when given as monotherapy except safinamide, but selegiline remained the best option in combination with levodopa [117]. Due to the lack of exact data from the head-to-head RCTs which have compared one MAO-B inhibitor to another, the conclusions drawn from meta-analyses are still needed to be validated in further trials.

\section{SAFETY OF MAO-B INHIBITORS}

The overall conclusions from evidence-based medicine recommendations are that the number of side-effects and the proportion of patients withdrawing from treatment because of poor tolerability are higher with DAs than with MAO-B inhibitors or levodopa in early PD [118]. MAO-B inhibitors have a low frequency of specific adverse events, and DAs are at a higher risk of excessive somnolence, hallucinations, and impulse-control disorders [119]. Regarding monotherapy, one randomized controlled trial suggested that the incidences of treatment-emergent adverse events (TEAEs) leading to withdrawal were slightly lower in the rasagiline group $(4.6 \%)$ than in placebo-treated individuals (7.7\%) [58]. Regarding combination treatments, moderate-quality evidence suggested that COMT inhibitors and DAs significantly increase the rates of AEs compared with placebo [9]. In addition, COMT inhibitors increased the rates of AEs compared with MAO-B inhibitors and DAs. The PD-MED study showed that in PD patients with DAs or MAO-B inhibitors, the rates of dyskinesia were similar (HR 0.85, 95\% CI 0.60-1.22, $p=0.40$ ), but motor fluctuations were higher (HR $1.32,95 \%$ CI $1.01-1.72, p=0.04$ ) in the DA group than in the MAO-B inhibitors group [51]. In general, MAO-B inhibitors could be used in long-term management of PD patients, as monotherapy for early PD and adjunct therapy for advanced PD.

\section{Selegiline}

It has been reported that PD patients treated with selegiline had a risk of "cheese reaction" and toxic effects on the cardiovascular system [120, 121], which was reported leading to increased mortality when selegiline was combined with levodopa [122]. However, this finding of increased mortality caused by selegiline is controversial. No significant increase in mortality was observed in later metaanalysis and good tolerability of MAO-B inhibitors was confirmed. A meta-analysis did not find that excess deaths occurred with MAO-B inhibitors compared with the control arm (20\% vs. $21 \%$ deaths, OR 1.13, 95\%CI [0.94, 1.34], $p=0.2$ ) [123]. Another meta-analysis showed that selegiline plus levodopa therapy was superior to levodopa monotherapy for the improvement of clinical symptoms in PD patients, without a significant increase in the number of AEs [124]. Though Jiang et al [124] found that selegiline plus levodopa combination therapy increased the mortality significantly compared with levodopa monotherapy (OR 1.73, 95\% CI 1.20 2.49, $p=0.003$ ), the difference between the two groups became statistically insignificant after excluding the Lee's study.

A study investigating the effects of selegiline in adjunct with levodopa on the cardiovascular system in PD patients showed a significant increase in plasma norepinephrine levels in patients acutely loaded with selegiline in adjunct with levodopa compared with levodopa monotherapy and healthy controls $(p<0.001)$, and the incidence of orthostatic hypotension was increased in PD patients, but the difference between groups was not statistically significant [125]. In addition, selegiline tended to cause hallucinations. The severity of hallucinations was significantly related to the duration of illness, Hoehn and Yahr stage, doses of levodopa. High dose of selegiline alone was enough to cause hallucination in PD patients even with a low dose of levodopa ( $\leq 300 \mathrm{mg} /$ day), a low Hoehn and Yahr stage, or a short duration of illness ( $\leq 8$ years) [126]. The occurrence of serotonin syndrome in 4568 patients on selegiline treatment receiving selective serotonin reuptake inhibitors (SSRIs) was found to be $0.24 \%$, with $0.04 \%$ presenting with severe symptoms [127]. Thus, it is advisable to instruct patients taking selegiline to avoid excessive intake of tyramine-rich foods. We should be cautious to prescribe selegiline to those PD patients taking SSRIs, having postural hypotension, cardiovascular diseases and hallucinations. 


\section{Rasagiline}

Rasagiline is well tolerated both in monotherapy and in combination with levodopa, with nasopharyngitis, fall, eczema, headache, and contusion being the most frequently reported adverse effects in monotherapy, and fall, nasopharyngitis, and dyskinesia in add-on therapy [60, 78]. With no risk of tyramine interaction or sympathomimetic effects, the longterm safety and efficacy of rasagiline have been proven either as monotherapy or adjunct to levodopa treatment. Up to 52 weeks, rasagiline was well tolerated with sustained motor symptom improvement $[60,78]$. On the association between rasagiline and antidepressants in PD patients, retrospective analysis of data from 1504 PD patients in the STACCATO study [128] showed that the mean duration of antidepressant use was 50.5 to 53.5 weeks in patients treated with rasagiline in adjunct with antidepressants, among which, SSRIs were used in up to $77 \%$ of these patients, and patients did not develop serotonin syndrome during adjunct therapy. However, the risk of the combination cannot be completely eliminated.

\section{Safinamide}

Safinamide was well tolerated in different randomized controlled trials and observational studies with similar incidences of TEAEs compared with placebo, most of which were mild to moderate [129]. A long-term safety and efficacy study of safinamide as add-on therapy to levodopa enrolled 203 Japanese PD patients with wearing-off, 142 of whom completed 52 weeks of treatment. The results showed that the incidence of adverse reactions was $78.3 \%$. The most common adverse reactions were nasopharyngitis (20.7\%) and dyskinesia (17.7\%) [130]. Another randomized, double-blind, placebo-controlled Phase II/III study in Japanese PD patients [82] showed that the incidence of adverse reactions was $58.9 \%$, $60.2 \%$, and $61.4 \%$ in the placebo group, $50 \mathrm{mg} /$ day and $100 \mathrm{mg} /$ day safinamide groups, respectively, and the most common adverse reactions were dyskinesia $(2.1 \%, 8.3 \%$ vs. $10.6 \%)$ and visual hallucinations (1.4\%, $3.0 \%$ vs. $4.5 \%)$. In 2021, a European realworld study to assess the safety of safinamide in PD patients [131] showed that the adverse events in treated patients were predominantly mild $(62.0 \%)$ or moderate $(28.0 \%)$, and only $2 \%$ were related to safinamide, and in most cases, these adverse events did not need to be treated. As an adjuvant therapy, safinamide is safe and well-tolerated in patients with fluctuating symptoms and in special populations.

\section{FUTURE OF MAO-B INHIBITORS}

Despite numerous clinical trials, PD remains an untreatable disease. Neuroprotection in PD has intended to halt or reverse cell death of nigrostriatal dopaminergic neurons and prevent disease progression, but clinical studies have not presented enough supporting results, except for the trial of rasagiline by delayed start design at a low dose of only $1 \mathrm{mg} /$ day. MAO-B inhibitors selegiline and rasagiline can both exhibit potent neuroprotective function by regulating mitochondrial apoptosis cascade, maintaining the mitochondrial function, and increasing gene coding expression of antioxidant enzymes, anti-apoptotic Bcl-2, and pro-survival neurotrophic factors, and suppressing oligomerization and aggregation of $\alpha$ synuclein and cell toxicity [132]. In addition to the traditional oral dosage forms, other novel galenic forms of MAO-B inhibitors were explored. Pharmacokinetic studies in healthy Chinese populations showed that the transdermal rasagiline patch was able to prolong the duration of administration with good safety and tolerability, providing a continuous treatment modality for patients who were not able to routinely take oral medications [133]. Furthermore, animal studies showed that injectable rasagiline based on an injectable long-acting formulation system significantly increases dopamine levels in PD model rats $(p<0.05)$ and effectively improves motor symptoms [134]. Encapsulation rasagiline in polycaprolactone microspheres prolonged drug release for 1 month by a single subcutaneous dose, and no significant difference was found with daily rasagiline administration in animal studies [135]. These studies suggest that new forms of MAO-B inhibitors could help improve the bioavailability of the drug, maintain the plasma concentration, improve patient compliance, and are also important for patients with dysphagia.

MAO-B inhibitors have now evolved into the third generation with higher selectivity, reversible effects, wider safety margins, and potential for neuroprotection, and their clinical efficacy is worth exploring [136]. Recent data show that monoamine oxidase remains a preferred molecular target in the study of neurodegenerative diseases [137]. Many novel MAO$\mathrm{B}$ inhibitors with high reversibility, selectivity, and 
fewer adverse effects are still under development $[137,138]$. There are also a large number of selective MAO-B inhibitors in natural products waiting to be discovered, including flavonoids, xanthones, proanthocyanidins iridoid, glucosides, curcumin, alkaloids and their derivatives [24]. Danshensu (3-(3,4-dihydroxyphenyl)-(2R)-lactic acid, salvianic acid A), which was isolated from several herbs, such as Salvia miltiorrhiza and Prunella vulgaris var. lilacina, was found to inhibit the activity of MAO-A and MAO-B [139, 140]. Danshensu treatment significantly increased the dopamine level in the cortex of the brain, improved scopolamine and $\mathrm{A} \beta$-induced cognitive impairments in mice [140]. In addition, the development of multitarget drugs based on MAO-B inhibitors in recent years, such as compounds with dual inhibition of MAO-B and cholinesterase, is expected to provide new hope for the treatment of neurodegenerative diseases such as PD and Alzheimer's disease [141, 142].

In addition to the treatment of PD patients, MAO-B inhibitors have attracted extensive attention in other diseases related to aging and apoptosis. Rasagiline was well tolerated in randomized controlled studies in patients with amyotrophic lateral sclerosis. The results of a post hoc analysis showed that rasagiline has the potential to protect patients with rapidly progressive amyotrophic lateral sclerosis [143]. MAO-B inhibitors also have potential anticancer activity, such as inhibiting glioma proliferation and significantly reducing glioma cell migration, and basic studies have shown that rasagiline can inhibit melanoma growth [144, 145].

\section{SUMMARY/EXPERT OPINIONS}

Many studies have shown that MAO-B inhibitors are effective and safe for patients with early and advanced PD. This medication can effectively improve patients' motor and non-motor symptoms and reduce the "OFF" time, with neuroprotective potential at the same time. It can also meet the patients' need for long-term and standardized treatment and provide more options for the whole course management of PD patients [146, 147]. In addition, a variety of new MAO-B inhibitors with higher selectivity, safety, and neuroprotection are under development. It is believed that with further study, MAO-B inhibitors will bring more profound benefits to patients being treated for neurodegenerative diseases such as PD.

\section{ACKNOWLEDGMENTS}

This work was supported by the National Natural Science Foundation of China, Grant/Award Number: 81430022, 81771374, 81971187, 81971183; Shanghai Municipal Science and Technology Major Project, Grant/Award Number: 2018SHZDZX05; Innovation Program of Shanghai Municipal Education Commission, Grant/Award Number: 2017-0107-00-01-E00046; Foundation of Shanghai Municipal Education Commission, Grant/Award Number: 2017 NKX001.

\section{CONFLICT OF INTEREST}

The authors have no conflict of interests.

\section{REFERENCES}

[1] Hayes MT (2019) Parkinson's disease and parkinsonism. Am J Med 132, 802-807.

[2] Dickson DW (2018) Neuropathology of Parkinson disease. Parkinsonism Relat Disord 46(Suppl 1), S30-S33.

[3] Raza C, Anjum R, Shakeel N (2019) Parkinson's disease: Mechanisms, translational models and management strategies. Life Sci 226, 77-90.

[4] (2018) Global, regional, and national burden of Parkinson's disease, 1990-2016: a systematic analysis for the Global Burden of Disease Study 2016. Lancet Neurol 17, 939-953.

[5] Santos García D, de Deus Fonticoba T, Suárez Castro E, Borrué C, Mata M, Solano Vila B, Cots Foraster A, Álvarez Sauco M, Rodríguez Pérez AB, Vela L, Macías Y, Escalante S, Esteve P, Reverté Villarroya S, Cubo E, Casas E, Arnaiz S, Carrillo Padilla F, Pueyo Morlans M, Mir P, Martinez-Martin P (2019) Non-motor symptoms burden, mood, and gait problems are the most significant factors contributing to a poor quality of life in non-demented Parkinson's disease patients: Results from the COPPADIS Study Cohort. Parkinsonism Relat Disord 66, 151-157.

[6] Sun Q, Wang T, Jiang TF, Huang P, Wang Y, Xiao Q, Liu J, Chen SD (2018) Clinical profile of Chinese longterm Parkinson's disease survivors with 10 years of disease duration and beyond. Aging Dis 9, 8-16.

[7] Kalia LV, Lang AE (2015) Parkinson's disease. Lancet 386, 896-912.

[8] Chen S, Chan P, Sun S, Chen H, Zhang B, Le W, Liu C, Peng G, Tang B, Wang L, Cheng Y, Shao M, Liu Z, Wang Z, Chen X, Wang M, Wan X, Shang H, Liu Y, Xu P, Wang J, Feng T, Chen X, Hu X, Xie A, Xiao Q (2016) The recommendations of Chinese Parkinson's disease and movement disorder society consensus on therapeutic management of Parkinson's disease. Transl Neurodegener 5, 12.

[9] Tambasco N, Romoli M, Calabresi P (2018) Levodopa in Parkinson's disease: current status and future developments. Curr Neuropharmacol 16, 1239-1252.

[10] Gershanik OS (2015) Improving L-dopa therapy: the development of enzyme inhibitors. Mov Disord 30, 103-113. 
[11] Chang Y, Wang LB, Li D, Lei K, Liu SY (2017) Efficacy of rasagiline for the treatment of Parkinson's disease: an updated meta-analysis. Ann Med 49, 421-434.

[12] (2002) A controlled trial of rasagiline in early Parkinson disease: the TEMPO Study. Arch Neurol 59, 19371943.

[13] (2005) A randomized placebo-controlled trial of rasagiline in levodopa-treated patients with Parkinson disease and motor fluctuations: the PRESTO study. Arch Neurol 62, 241-248.

[14] Hauser RA, Li R, Pérez A, Ren X, Weintraub D, Elm J, Goudreau JL, Morgan JC, Fang JY, Aminoff MJ, Christine CW, Dhall R, Umeh CC, Boyd JT, Stover N, Leehey M, Zweig RM, Nicholas AP, Bodis-Wollner I, Willis A, Kieburtz K, Tilley BC (2017) Longer duration of MAO-B inhibitor exposure is associated with less clinical decline in Parkinson's disease: an analysis of NET-PD LS1. $J$ Parkinsons Dis 7, 117-127.

[15] Cereda E, Cilia R, Canesi M, Tesei S, Mariani CB, Zecchinelli AL, Pezzoli G (2017) Efficacy of rasagiline and selegiline in Parkinson's disease: a head-to-head 3-year retrospective case-control study. J Neurol 264, 1254-1263.

[16] Alborghetti M, Nicoletti F (2019) Different generations of type-B monoamine oxidase inhibitors in Parkinson's disease: from bench to bedside. Curr Neuropharmacol 17, 861-873.

[17] Shih JC (2018) Monoamine oxidase isoenzymes: genes, functions and targets for behavior and cancer therapy. $J$ Neural Transm (Vienna) 125, 1553-1566.

[18] Bortolato M, Chen K, Shih JC (2008) Monoamine oxidase inactivation: from pathophysiology to therapeutics. $A d v$ Drug Deliv Rev 60, 1527-1533.

[19] Carradori S, Secci D, Petzer JP (2018) MAO inhibitors and their wider applications: a patent review. Expert Opin Ther Pat 28, 211-226.

[20] Stocchi F, Fossati C, Torti M (2015) Rasagiline for the treatment of Parkinson's disease: an update. Expert Opin Pharmacother 16, 2231-2241.

[21] Chen JJ, Swope DM (2005) Clinical pharmacology of rasagiline: a novel, second-generation propargylamine for the treatment of Parkinson disease. J Clin Pharmacol 45, 878-894.

[22] Bainbridge JL, Page RL 2nd, Ruscin JM (2008) Elucidating the mechanism of action and potential interactions of MAO-B inhibitors. Neurol Clin 26, S85-96, vi.

[23] Fowler CJ, Wiberg A, Oreland L, Marcusson J, Winblad B (1980) The effect of age on the activity and molecular properties of human brain monoamine oxidase. J Neural Transm 49, 1-20.

[24] Carradori S, D'Ascenzio M, Chimenti P, Secci D, Bolasco A (2014) Selective MAO-B inhibitors: a lesson from natural products. Mol Divers 18, 219-243.

[25] Heo JY, Nam MH, Yoon HH, Kim J, Hwang YJ, Won W, Woo DH, Lee JA, Park HJ, Jo S, Lee MJ, Kim S, Shim JE, Jang DP, Kim KI, Huh SH, Jeong JY, Kowall NW, Lee J, Im H, Park JH, Jang BK, Park KD, Lee HJ, Shin H, Cho IJ, Hwang EM, Kim Y, Kim HY, Oh SJ, Lee SE, Paek $\mathrm{SH}$, Yoon JH, Jin BK, Kweon GR, Shim I, Hwang O, Ryu H, Jeon SR, Lee CJ (2020) Aberrant tonic inhibition of dopaminergic neuronal activity causes motor symptoms in animal models of Parkinson's disease. Curr Biol 30, 276-291.e9.

[26] Youdim MB, Gross A, Finberg JP (2001) Rasagiline [N-propargyl-1R(+)-aminoindan], a selective and potent inhibitor of mitochondrial monoamine oxidase B. $\mathrm{Br} J$ Pharmacol 132, 500-506.

[27] Pohl P, Wressle E, Lundin F, Enthoven P, Dizdar N (2020) Group-based music intervention in Parkinson's disease findings from a mixed-methods study. Clin Rehabil 34, 533-544.

[28] (1993) Effects of tocopherol and deprenyl on the progression of disability in early Parkinson's disease. $N$ Engl $J$ Med 328, 176-183.

[29] Shoulson I, Oakes D, Fahn S, Lang A, Langston JW, LeWitt P, Olanow CW, Penney JB, Tanner C, Kieburtz K, Rudolph A (2002) Impact of sustained deprenyl (selegiline) in levodopa-treated Parkinson's disease: a randomized placebo-controlled extension of the deprenyl and tocopherol antioxidative therapy of parkinsonism trial. Ann Neurol 51, 604-612.

[30] Teixeira FG, Gago MF, Marques P, Moreira PS, Magalhães R, Sousa N, Salgado AJ (2018) Safinamide: a new hope for Parkinson's disease. Drug Discov Today 23, 736-744.

[31] Müller T (2017) Pharmacokinetic drug evaluation of safinamide mesylate for the treatment of mid-to-late stage Parkinson's disease. Expert Opin Drug Metab Toxicol 13, 693-699.

[32] Gardoni F, Morari M, Kulisevsky J, Brugnoli A, Novello S, Pisanò CA, Caccia C, Mellone M, Melloni E, Padoani G, Sosti V, Vailati S, Keywood C (2018) Safinamide modulates striatal glutamatergic signaling in a rat model of levodopa-induced dyskinesia. J Pharmacol Exp Ther 367, 442-451.

[33] Seidl SE, Potashkin JA (2011) The promise of neuroprotective agents in Parkinson's disease. Front Neurol 2, 68.

[34] Carrera I, Cacabelos R (2019) Current drugs and potential future neuroprotective compounds for Parkinson's disease. Curr Neuropharmacol 17, 295-306.

[35] Weinreb O, Amit T, Riederer P, Youdim MB, Mandel SA (2011) Neuroprotective profile of the multitarget drug rasagiline in Parkinson's disease. Int Rev Neurobiol 100, 127-149.

[36] Weinreb O, Amit T, Bar-Am O, Youdim MB (2010) Rasagiline: a novel anti-Parkinsonian monoamine oxidase-B inhibitor with neuroprotective activity. Prog Neurobiol 92, 330-344.

[37] Abu-Raya S, Tabakman R, Blaugrund E, Trembovler V, Lazarovici P (2002) Neuroprotective and neurotoxic effects of monoamine oxidase-B inhibitors and derived metabolites under ischemia in PC12 cells. Eur J Pharmacol 434, 109-116.

[38] Badinter F, Amit T, Bar-Am O, Youdim MB, Weinreb O (2015) Beneficial behavioral, neurochemical and molecular effects of 1-(R)-aminoindan in aged mice. $\mathrm{Neu}$ ropharmacology $99,264-272$.

[39] Weinreb O, Bar-Am O, Amit T, Chillag-Talmor O, Youdim MB (2004) Neuroprotection via pro-survival protein kinase $\mathrm{C}$ isoforms associated with $\mathrm{Bcl}-2$ family members. FASEB J 18, 1471-1473.

[40] Im JJ, Jeong H, Chung YA, Park JS, Heo Y, Oh JK, Song IU (2019) Neuroprotective effects of rasagiline in Parkinson's disease: a regional cerebral blood flow study. JNeuroimaging 29, 707-711.

[41] Sadeghian M, Mullali G, Pocock JM, Piers T, Roach A, Smith KJ (2016) Neuroprotection by safinamide in the 6-hydroxydopamine model of Parkinson's disease. $\mathrm{Neu}$ ropathol Appl Neurobiol 42, 423-435.

[42] Faustini G, Bono F, Valerio A, Pizzi M, Spano P, Bellucci A (2017) Mitochondria and $\alpha$-synuclein: friends or foes 
in the pathogenesis of Parkinson's disease. Genes (Basel) 8, 377 .

[43] Czerniczyniec A, Bustamante J, Lores-Arnaiz S (2006) Modulation of brain mitochondrial function by deprenyl. Neurochem Int 48, 235-241.

[44] Wu Y, Kazumura K, Maruyama W, Osawa T, Naoi M (2015) Rasagiline and selegiline suppress calcium efflux from mitochondria by PK11195-induced opening of mitochondrial permeability transition pore: a novel antiapoptotic function for neuroprotection. J Neural Transm (Vienna) 122, 1399-1407.

[45] Langston JW (2017) The MPTP story. J Parkinsons Dis 7, S11-S19.

[46] Kupsch A, Sautter J, Götz ME, Breithaupt W, Schwarz J, Youdim MB, Riederer P, Gerlach M, Oertel WH (2001) Monoamine oxidase-inhibition and MPTP-induced neurotoxicity in the non-human primate: comparison of rasagiline (TVP 1012) with selegiline. J Neural Transm (Vienna) 108, 985-1009.

[47] Braga CA, Follmer C, Palhano FL, Khattar E, Freitas MS, Romão L, Di Giovanni S, Lashuel HA, Silva JL, Foguel D (2011) The anti-Parkinsonian drug selegiline delays the nucleation phase of $\alpha$-synuclein aggregation leading to the formation of nontoxic species. J Mol Biol 405, 254-273.

[48] Kakish J, Tavassoly O, Lee JS (2015) Rasagiline, a suicide inhibitor of monoamine oxidases, binds reversibly to $\alpha$ synuclein. ACS Chem Neurosci 6, 347-355.

[49] Fox SH, Katzenschlager R, Lim SY, Barton B, de Bie R, Seppi K, Coelho M, Sampaio C (2018) International Parkinson and movement disorder society evidence-based medicine review: Update on treatments for the motor symptoms of Parkinson's disease. Mov Disord 33, 12481266.

[50] Chinese Society of Parkinson's Disease and Movement Disorders (2020) Chinese guidelines for the treatment of Parkinson's disease (fourth edition). Chin J Neurol 12, 973-984.

[51] Gray R, Ives N, Rick C, Patel S, Gray A, Jenkinson C, McIntosh E, Wheatley K, Williams A, Clarke CE (2014) Long-term effectiveness of dopamine agonists and monoamine oxidase B inhibitors compared with levodopa as initial treatment for Parkinson's disease (PD MED): a large, open-label, pragmatic randomised trial. Lancet 384, 1196-1205.

[52] Tetrud JW, Langston JW (1989) The effect of deprenyl (selegiline) on the natural history of Parkinson's disease. Science 245, 519-522.

[53] Myllylä VV, Sotaniemi KA, Vuorinen JA, Heinonen EH (1992) Selegiline as initial treatment in de novo parkinsonian patients. Neurology 42, 339-343.

[54] Pålhagen S, Heinonen EH, Hägglund J, Kaugesaar T, Kontants H, Mäki-Ikola O, Palm R, Turunen J (1998) Selegiline delays the onset of disability in de novo parkinsonian patients. Swedish Parkinson Study Group. Neurology 51, 520-525.

[55] Mizuno Y, Hattori N, Kondo T, Nomoto M, Origasa H, Takahashi R, Yamamoto M, Yanagisawa N (2017) A randomized double-blind placebo-controlled phase III trial of selegiline monotherapy for early Parkinson disease. Clin Neuropharmacol 40, 201-207.

[56] Lew MF, Hauser RA, Hurtig HI, Ondo WG, Wojcieszek J, Goren T, Fitzer-Attas CJ (2010) Long-term efficacy of rasagiline in early Parkinson's disease. Int J Neurosci 120, 404-408.
[57] Olanow CW, Rascol O, Hauser R, Feigin PD, Jankovic J, Lang A, Langston W, Melamed E, Poewe W, Stocchi F, Tolosa E (2009) A double-blind, delayed-start trial of rasagiline in Parkinson's disease. N Engl J Med 361, 1268 1278.

[58] Zhang Z, Wang J, Chen S, Liu C, Zhang B, Peng R, Sun S, Sun X, Zhao G, Qu Q, Li Y, Zhu S, Pan X, Shao M, Wang Y (2018) Efficacy and safety of rasagiline in Chinese patients with early Parkinson's disease: a randomized, double-blind, parallel, placebo-controlled, fixed-dose study. Transl Neurodegener 7, 32.

[59] Hattori N, Takeda A, Takeda S, Nishimura A, Kitagawa T, Mochizuki H, Nagai M, Takahashi R (2019) Rasagiline monotherapy in early Parkinson's disease: A phase 3, randomized study in Japan. Parkinsonism Relat Disord 60, 146-152.

[60] Hattori N, Takeda A, Takeda S, Nishimura A, Kitagawa T, Mochizuki H, Nagai M, Takahashi R (2019) Long-term, open-label, phase 3 study of rasagiline in Japanese patients with early Parkinson's disease. J Neural Transm (Vienna) 126, 299-308

[61] Shoulson I (1992) An interim report of the effect of selegiline (L-deprenyl) on the progression of disability in early Parkinson's disease. The Parkinson Study Group. Eur Neurol 32(Suppl 1), 46-53.

[62] Przuntek H, Conrad B, Dichgans J, Kraus PH, Krauseneck P, Pergande G, Rinne U, Schimrigk K, Schnitker J, Vogel HP (1999) SELEDO: a 5-year long-term trial on the effect of selegiline in early Parkinsonian patients treated with levodopa. Eur J Neurol 6, 141-150.

[63] Pålhagen S, Heinonen E, Hägglund J, Kaugesaar T, MäkiIkola O, Palm R (2006) Selegiline slows the progression of the symptoms of Parkinson disease. Neurology 66, 12001206.

[64] Nappi G, Martignoni E, Horowski R, Pacchetti C, Rainer E, Bruggi P, Runge I (1991) Lisuride plus selegiline in the treatment of early Parkinson's disease. Acta Neurol Scand 83, 407-410.

[65] Calzetti S, Negrotti A, Cassio A (1995) L-deprenyl as an adjunct to low-dose bromocriptine in early Parkinson's disease: a short-term, double-blind, and prospective follow-up study. Clin Neuropharmacol 18, 250-257.

[66] Lyons KE, Friedman JH, Hermanowicz N, Isaacson SH, Hauser RA, Hersh BP, Silver DE, Tetrud JW, Elmer LW, Parashos SA, Struck LK, Lew MF, Pahwa R (2010) Orally disintegrating selegiline in Parkinson patients with dopamine agonist-related adverse effects. Clin Neuropharmacol 33, 5-10.

[67] Hauser RA, Silver D, Choudhry A, Eyal E, Isaacson S (2014) Randomized, controlled trial of rasagiline as an add-on to dopamine agonists in Parkinson's disease. Mov Disord 29, 1028-1034.

[68] Olanow CW, Kieburtz K, Leinonen M, Elmer L, Giladi N, Hauser RA, Klepiskaya OS, Kreitzman DL, Lew MF, Russell DS, Kadosh S, Litman P, Friedman H, Linvah N, For The P B Study Group (2017) A randomized trial of a lowdose Rasagiline and Pramipexole combination (P2B001) in early Parkinson's disease. Mov Disord 32, 783-789.

[69] Stocchi F, Borgohain R, Onofrj M, Schapira AH, Bhatt M, Lucini V, Giuliani R, Anand R (2012) A randomized, double-blind, placebo-controlled trial of safinamide as add-on therapy in early Parkinson's disease patients. Mov Disord 27, 106-112.

[70] Schapira AH, Stocchi F, Borgohain R, Onofrj M, Bhatt M, Lorenzana P, Lucini V, Giuliani R, Anand R (2013) Long- 
term efficacy and safety of safinamide as add-on therapy in early Parkinson's disease. Eur J Neurol 20, 271-280.

[71] Golbe LI, Lieberman AN, Muenter MD, Ahlskog JE, Gopinathan G, Neophytides AN, Foo SH, Duvoisin RC (1988) Deprenyl in the treatment of symptom fluctuations in advanced Parkinson's disease. Clin Neuropharmacol 11, 45-55.

[72] Cedarbaum JM, Toy LH, Green-Parsons A (1991) Ldeprenyl (selegiline) added to Sinemet $\mathrm{CR}$ in the management of Parkinson's disease patients with motor response fluctuations. Clin Neuropharmacol 14, 228-234.

[73] Rascol O, Brooks DJ, Melamed E, Oertel W, Poewe W, Stocchi F, Tolosa E (2005) Rasagiline as an adjunct to levodopa in patients with Parkinson's disease and motor fluctuations (LARGO, Lasting effect in Adjunct therapy with Rasagiline Given Once daily, study): a randomised, double-blind, parallel-group trial. Lancet 365, 947-954.

[74] Stocchi F, Rabey JM (2011) Effect of rasagiline as adjunct therapy to levodopa on severity of OFF in Parkinson's disease. Eur J Neurol 18, 1373-1378.

[75] Zhang L, Zhang Z, Chen Y, Qin X, Zhou H, Zhang C, Sun H, Tang R, Zheng J, Yi L, Deng L, Li J (2013) Efficacy and safety of rasagiline as an adjunct to levodopa treatment in Chinese patients with Parkinson's disease: a randomized, double-blind, parallel-controlled, multi-centre trial. Int $J$ Neuropsychopharmacol 16, 1529-1537.

[76] Zhang Z, Shao M, Chen S, Liu C, Peng R, Li Y, Wang J, Zhu S, Qu Q, Zhang X, Chen H, Sun X, Wang Y, Sun S, Zhang B, Li J, Pan X, Zhao G (2018) Adjunct rasagiline to treat Parkinson's disease with motor fluctuations: a randomized, double-blind study in China. Transl Neurodegener 7,14

[77] Hattori N, Takeda A, Takeda S, Nishimura A, Kato M, Mochizuki H, Nagai M, Takahashi R (2018) Efficacy and safety of adjunctive rasagiline in Japanese Parkinson's disease patients with wearing-off phenomena: A phase 2/3, randomized, double-blind, placebo-controlled, multicenter study. Parkinsonism Relat Disord 53, 21-27.

[78] Hattori N, Takeda A, Takeda S, Nishimura A, Nakaya R, Mochizuki H, Nagai M, Takahashi R (2019) Long-term safety and efficacy of adjunctive rasagiline in levodopatreated Japanese patients with Parkinson's disease. $J$ Neural Transm (Vienna) 126, 289-297.

[79] Müller T, Riederer P, Grünblatt E (2017) Determination of monoamine oxidase A and B activity in long-term treated patients with Parkinson disease. Clin Neuropharmacol 40, 208-211.

[80] Borgohain R, Szasz J, Stanzione P, Meshram C, Bhatt M, Chirilineau D, Stocchi F, Lucini V, Giuliani R, Forrest E, Rice P, Anand R (2014) Randomized trial of safinamide add-on to levodopa in Parkinson's disease with motor fluctuations. Mov Disord 29, 229-237.

[81] Schapira AH, Fox SH, Hauser RA, Jankovic J, Jost WH, Kenney C, Kulisevsky J, Pahwa R, Poewe W, Anand R (2017) Assessment of safety and efficacy of safinamide as a levodopa adjunct in patients with Parkinson disease and motor fluctuations: a randomized clinical trial. JAMA Neurol 74, 216-224.

[82] Hattori N, Tsuboi Y, Yamamoto A, Sasagawa Y, Nomoto M (2020) Efficacy and safety of safinamide as an add-on therapy to L-DOPA for patients with Parkinson's disease: A randomized, double-blind, placebo-controlled, phase II/III study. Parkinsonism Relat Disord 75, 17-23.

[83] Breen DP, Vuono R, Nawarathna U, Fisher K, Shneerson JM, Reddy AB, Barker RA (2014) Sleep and circadian rhythm regulation in early Parkinson disease. JAMA Neurol 71, 589-595.

[84] Zhu K, van Hilten JJ, Marinus J (2016) The course of insomnia in Parkinson's disease. Parkinsonism Relat Disord 33, 51-57.

[85] Stefani A, Högl B (2020) Sleep in Parkinson's disease. Neuropsychopharmacology 45, 121-128.

[86] Heinonen EH, Myllylä V (1998) Safety of selegiline (deprenyl) in the treatment of Parkinson's disease. Drug Saf 19, 11-22.

[87] Müller T, Hoffmann JA, Dimpfel W, Oehlwein C (2013) Switch from selegiline to rasagiline is beneficial in patients with Parkinson's disease. J Neural Transm (Vienna) 120. 761-765.

[88] Gallazzi M, Mauri M, Bianchi ML, Riboldazzi G, Princiotta Cariddi L, Carimati F, Rebecchi V, Versino M (2021) Selegiline reduces daytime sleepiness in patients with Parkinson's disease. Brain Behav 11, e01880.

[89] Schettino C, Dato C, Capaldo G, Sampaolo S, Di Iorio G, Melone MA (2016) Rasagiline for sleep disorders in patients with Parkinson's disease: a prospective observational study. Neuropsychiatr Dis Treat 12, 2497 2502.

[90] Schrempf W, Fauser M, Wienecke M, Brown S, Maaß A, Ossig C, Otto K, Brandt MD, Löhle M, Schwanebeck U, Graehlert X, Reichmann H, Storch A (2018) Rasagiline improves polysomnographic sleep parameters in patients with Parkinson's disease: a double-blind, baselinecontrolled trial. Eur J Neurol 25, 672-679.

[91] Liguori C, Mercuri NB, Stefani A, Pierantozzi M (2018) Effective treatment of restless legs syndrome by safinamide in Parkinson's disease patients. Sleep Med 41, 113-114.

[92] Liguori C, Stefani A, Ruffini R, Mercuri NB, Pierantozzi M (2018) Safinamide effect on sleep disturbances and daytime sleepiness in motor fluctuating Parkinson's disease patients: A validated questionnaires-controlled study. Parkinsonism Relat Disord 57, 80-81.

[93] Santos García D, Labandeira Guerra C, Yáñez Baña R, Cimas Hernando MI, Cabo López I, Paz Gonález JM, Alonso Losada MG, González Palmás MJ, Martínez Miró C (2021) Safinamide improves non-motor symptoms burden in Parkinson's disease: an open-label prospective study. Brain Sci 11, 316.

[94] Bianchi M, Riboldazzi G, Mauri M, Versino M (2019) Efficacy of safinamide on non-motor symptoms in a cohort of patients affected by idiopathic Parkinson's disease. Neurol Sci 40, 275-279.

[95] Siciliano M, Trojano L, Santangelo G, De Micco R, Tedeschi G, Tessitore A (2018) Fatigue in Parkinson's disease: A systematic review and meta-analysis. Mov Disord 33, 1712-1723.

[96] Lazcano-Ocampo C, Wan YM, van Wamelen DJ, Batzu L, Boura I, Titova N, Leta V, Qamar M, Martinez-Martin P, Ray Chaudhuri K (2020) Identifying and responding to fatigue and apathy in Parkinson's disease: a review of current practice. Expert Rev Neurother 20, 477-495.

[97] Stocchi F (2014) Benefits of treatment with rasagiline for fatigue symptoms in patients with early Parkinson's disease. Eur J Neurol 21, 357-360.

[98] Lim TT, Kluger BM, Rodriguez RL, Malaty IA, Palacio R Jr, Ojo OO, Patel S, Gujrati Y, Nutter B, Swartz C, Hennessy C, Fernandez HH (2015) Rasagiline for the symptomatic treatment of fatigue in Parkinson's disease. Mov Disord 30, 1825-1830. 
[99] Seppi K, Ray Chaudhuri K, Coelho M, Fox SH, Katzenschlager R, Perez Lloret S, Weintraub D, Sampaio C (2019) Update on treatments for nonmotor symptoms of Parkinson's disease-an evidence-based medicine review. Mov Disord 34, 180-198.

[100] De Micco R, Satolli S, Siciliano M, De Mase A, Giordano A, Tedeschi G, Tessitore A (2021) Effects of safinamide on non-motor, cognitive, and behavioral symptoms in fluctuating Parkinson's disease patients: a prospective longitudinal study. Neurol Sci, doi: 10.1007/s10072-02105324-w.

[101] Schapira A, Chaudhuri KR, Jenner P (2017) Non-motor features of Parkinson disease. Nat Rev Neurosci 18, 435-450.

[102] Huang YH, Chen JH, Loh EW, Chan L, Hong CT (2021) The effect of monoamine oxidase-B inhibitors on the alleviation of depressive symptoms in Parkinson's disease: meta-analysis of randomized controlled trials. Ther Adv Psychopharmacol 11, 2045125320985993.

[103] Allain H, Cougnard J, Neukirch HC (1991) Selegiline in de novo parkinsonian patients: the French selegiline multicenter trial (FSMT). Acta Neurol Scand Suppl 136, 73-78.

[104] Imamura K, Okayasu N, Nagatsu T (2011) The relationship between depression and regional cerebral blood flow in Parkinson's disease and the effect of selegiline treatment. Acta Neurol Scand 124, 28-39.

[105] Barone P, Santangelo G, Morgante L, Onofrj M, Meco G, Abbruzzese G, Bonuccelli U, Cossu G, Pezzoli G, Stanzione P, Lopiano L, Antonini A, Tinazzi M (2015) A randomized clinical trial to evaluate the effects of rasagiline on depressive symptoms in non-demented Parkinson's disease patients. Eur J Neurol 22, 1184-1191.

[106] Cattaneo C, Müller T, Bonizzoni E, Lazzeri G, Kottakis I, Keywood C (2017) Long-term effects of safinamide on mood fluctuations in Parkinson's disease. J Parkinsons Dis 7, 629-634.

[107] Brusa L, Musco S, Bernardi G, Iani C, Pierantozzi M, Stanzione P, Stefani A, Agro\&\#39 F, E (2014) Rasagiline effect on bladder disturbances in early mild Parkinson's disease patients. Parkinsonism Relat Disord 20, 931-932.

[108] Gómez-López A, Sánchez-Sánchez A, Natera-Villalba E, Ros-Castelló V, Beltrán-Corbellini Á, Fanjul-Arbós S, Pareés Moreno I, López-Sendon Moreno JL, Martínez Castrillo JC, Alonso-Canovas A (2021) SURINPARK: Safinamide for Urinary Symptoms in Parkinson's Disease. Brain Sci 11, 57.

[109] Mancini M, Bloem BR, Horak FB, Lewis S, Nieuwboer A, Nonnekes J (2019) Clinical and methodological challenges for assessing freezing of gait: Future perspectives. Mov Disord 34, 783-790.

[110] Ou R, Guo X, Song W, Cao B, Yang J, Wei Q, Shao N, Shang H (2014) Freezing of gait in Chinese patients with Parkinson disease. J Neurol Sci 345, 56-60.

[111] Nonnekes J, Snijders AH, Nutt JG, Deuschl G, Giladi N, Bloem BR (2015) Freezing of gait: a practical approach to management. Lancet Neurol 14, 768-778.

[112] Giladi N, McDermott MP, Fahn S, Przedborski S, Jankovic J, Stern M, Tanner C (2001) Freezing of gait in PD: prospective assessment in the DATATOP cohort. Neurology 56, 1712-1721.

[113] Elmer LW (2013) Rasagiline adjunct therapy in patients with Parkinson's disease: post hoc analyses of the PRESTO and LARGO trials. Parkinsonism Relat Disord 19, 930-936.
[114] Cibulcik F, Benetin J, Kurca E, Grofik M, Dvorak M, Richter D, Donath V, Kothaj J, Minar M, Valkovic P (2016) Effects of rasagiline on freezing of gait in Parkinson's disease - an open-label, multicenter study. Biomed Pap Med Fac Univ Palacky Olomouc Czech Repub 160, 549-552.

[115] Cattaneo C, Sardina M, Bonizzoni E (2016) Safinamide as add-on therapy to levodopa in mid- to late-stage Parkinson's disease fluctuating patients: post hoc analyses of studies 016 and SETTLE. J Parkinsons Dis 6, 165-173.

[116] Binde CD, Tvete IF, Gåsemyr J, Natvig B, Klemp M (2018) A multiple treatment comparison meta-analysis of monoamine oxidase type B inhibitors for Parkinson's disease. Br J Clin Pharmacol 84, 1917-1927.

[117] Binde CD, Tvete IF, Gåsemyr JI, Natvig B, Klemp M (2020) Comparative effectiveness of dopamine agonists and monoamine oxidase type-B inhibitors for Parkinson's disease: a multiple treatment comparison meta-analysis. Eur J Clin Pharmacol 76, 1731-1743.

[118] de Bie R, Clarke CE, Espay AJ, Fox SH, Lang AE (2020) Initiation of pharmacological therapy in Parkinson's disease: when, why, and how. Lancet Neurol 19, 452-461.

[119] Rogers G, Davies D, Pink J, Cooper P (2017) Parkinson's disease: summary of updated NICE guidance. BMJ 358, j1951.

[120] Montastruc JL, Chaumerliac C, Desboeuf K, Manika M, Bagheri H, Rascol O, Lapeyre-Mestre M (2000) Adverse drug reactions to selegiline: a review of the French pharmacovigilance database. Clin Neuropharmacol 23, 271-275.

[121] Churchyard A, Mathias CJ, Boonkongchuen P, Lees AJ (1997) Autonomic effects of selegiline: possible cardiovascular toxicity in Parkinson's disease. J Neurol Neurosurg Psychiatry 63, 228-234.

[122] (1993) Comparisons of therapeutic effects of levodopa, levodopa and selegiline, and bromocriptine in patients with early, mild Parkinson's disease: three year interim report. Parkinson's Disease Research Group in the United Kingdom. BMJ 307, 469-472.

[123] Ives NJ, Stowe RL, Marro J, Counsell C, Macleod A, Clarke CE, Gray R, Wheatley K (2004) Monoamine oxidase type B inhibitors in early Parkinson's disease: meta-analysis of 17 randomised trials involving 3525 patients. BMJ 329, 593.

[124] Jiang DQ, Li MX, Jiang LL, Chen XB, Zhou XW (2020) Comparison of selegiline and levodopa combination therapy versus levodopa monotherapy in the treatment of Parkinson's disease: a meta-analysis. Aging Clin Exp Res 32, 769-779.

[125] Stryjer R, Klein C, Treves TA, Rabey JM (2005) The effects of acute loading with levodopa and levodopa with selegiline on blood pressure and plasma norepinephrine levels in chronic Parkinson's disease patients. Acta Neurol Scand 111, 89-94.

[126] Kamakura K, Mochizuki H, Kaida K, Hirata A, Kanzaki M, Masaki T, Nakamura R, Motoyoshi K (2004) Therapeutic factors causing hallucination in Parkinson's disease patients, especially those given selegiline. Parkinsonism Relat Disord 10, 235-242.

[127] Richard IH, Kurlan R, Tanner C, Factor S, Hubble J, Suchowersky O, Waters C (1997) Serotonin syndrome and the combined use of deprenyl and an antidepressant in Parkinson's disease. Parkinson Study Group. Neurology 48, 1070-1077. 
[128] Panisset M, Chen JJ, Rhyee SH, Conner J, Mathena J (2014) Serotonin toxicity association with concomitant antidepressants and rasagiline treatment: retrospective study (STACCATO). Pharmacotherapy 34, 1250-1258.

[129] Pagonabarraga J, Arbelo JM, Grandas F, Luquin MR, Martínez Martín P, Rodríguez-Oroz MC, Valldeoriola F, Kulisevsky J (2020) A Spanish consensus on the use of safinamide for Parkinson's disease in clinical practice. Brain Sci 10, 176.

[130] Tsuboi Y, Hattori N, Yamamoto A, Sasagawa Y, Nomoto M (2020) Long-term safety and efficacy of safinamide as add-on therapy in levodopa-treated Japanese patients with Parkinson's disease with wearing-off: Results of an openlabel study. J Neurol Sci 416, 117012.

[131] Abbruzzese G, Kulisevsky J, Bergmans B, GomezEsteban JC, Kägi G, Raw J, Stefani A, Warnecke T, Jost WH (2021) A European observational study to evaluate the safety and the effectiveness of safinamide in routine clinical practice: The SYNAPSES Trial. J Parkinsons Dis 11, 187-198.

[132] Naoi M, Maruyama W, Shamoto-Nagai M (2020) Rasagiline and selegiline modulate mitochondrial homeostasis, intervene apoptosis system and mitigate $\alpha$-synuclein cytotoxicity in disease-modifying therapy for Parkinson's disease. J Neural Transm (Vienna) 127, 131-147.

[133] Zhou W, Lv C, Zhang Q, Zong S, Wang M (2018) Pharmacokinetics, pharmacodynamics, and safety of rasagiline transdermal patch: a preliminary study in healthy Chinese subjects. Clin Drug Investig 38, 125-133.

[134] Jiang Y, Zhang X, Mu H, Hua H, Duan D, Yan X, Wang Y, Meng Q, Lu X, Wang A, Liu W, Li Y, Sun K (2018) Preparation and evaluation of injectable Rasagiline mesylate dual-controlled drug delivery system for the treatment of Parkinson's disease. Drug Deliv 25, 143-152.

[135] Kanwar N, Bhandari R, Kuhad A, Sinha VR (2019) Polycaprolactone-based neurotherapeutic delivery of rasagiline targeting behavioral and biochemical deficits in Parkinson's disease. Drug Deliv Transl Res 9, 891-905.

[136] Blair HA, Dhillon S (2017) Safinamide: a review in Parkinson's disease. CNS Drugs 31, 169-176.

[137] Yeung A, Georgieva MG, Atanasov AG, Tzvetkov NT (2019) Monoamine oxidases (MAOs) as privileged molecular targets in neuroscience: research literature analysis. Front Mol Neurosci 12, 143.

[138] Tripathi R, Ayyannan SR (2019) Monoamine oxidaseB inhibitors as potential neurotherapeutic agents: An overview and update. Med Res Rev 39, 1603-1706.
[139] Son B, Jun SY, Seo H, Youn H, Yang HJ, Kim W, Kim HK, Kang C, Youn B (2016) Inhibitory effect of traditional oriental medicine-derived monoamine oxidase $\mathrm{B}$ inhibitor on radioresistance of non-small cell lung cancer. Sci Rep 6, 21986.

[140] Bae HJ, Sowndhararajan K, Park HB, Kim SY, Kim S, Kim DH, Choi JW, Jang DS, Ryu JH, Park SJ (2019) Danshensu attenuates scopolamine and amyloid- $\beta$-induced cognitive impairments through the activation of PKA-CREB signaling in mice. Neurochem Int 131, 104537.

[141] Carradori S, Ortuso F, Petzer A, Bagetta D, De Monte C, Secci D, De Vita D, Guglielmi P, Zengin G, Aktumsek A, Alcaro S, Petzer JP (2018) Design, synthesis and biochemical evaluation of novel multi-target inhibitors as potential anti-Parkinson agents. Eur J Med Chem 143, 1543-1552.

[142] He Q, Liu J, Lan JS, Ding J, Sun Y, Fang Y, Jiang N, Yang Z, Sun L, Jin Y, Xie SS (2018) Coumarin-dithiocarbamate hybrids as novel multitarget AChE and MAO-B inhibitors against Alzheimer's disease: Design, synthesis and biological evaluation. Bioorg Chem 81, 512-528.

[143] Ludolph AC, Schuster J, Dorst J, Dupuis L, Dreyhaupt J, Weishaupt JH, Kassubek J, Weiland U, Petri S, Meyer T, Grosskreutz J, Schrank B, Boentert M, Emmer A, Hermann A, Zeller D, Prudlo J, Winkler AS, Grehl T, Heneka MT, Wollebæk Johannesen S, Göricke B (2018) Safety and efficacy of rasagiline as an add-on therapy to riluzole in patients with amyotrophic lateral sclerosis: a randomised, double-blind, parallel-group, placebo-controlled, phase 2 trial. Lancet Neurol 17, 681-688.

[144] Marconi GD, Gallorini M, Carradori S, Guglielmi P, Cataldi A, Zara S (2019) The up-regulation of oxidative stress as a potential mechanism of novel MAO-B inhibitors for glioblastoma treatment. Molecules 24, 2005.

[145] Meier-Davis SR, Dines K, Arjmand FM, Hamlin R, Huang B, Wen J, Christianson C, Shudo J, Nagata T (2012) Comparison of oral and transdermal administration of rasagiline mesylate on human melanoma tumor growth in vivo. Cutan Ocul Toxicol 31, 312-317.

[146] Dezsi L, Vecsei L (2017) Monoamine oxidase B inhibitors in Parkinson's disease. CNS Neurol Disord Drug Targets 16, 425-439.

[147] Okun MS (2017) Management of Parkinson disease in 2017: personalized approaches for patient-specific needs. JAMA 318, 791-792. 